Article

\title{
Effects of High CaO Fly Ash and Sulfate Activator as a Finer Binder for Cementless Grouting Material
}

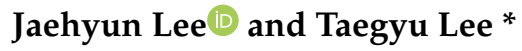 \\ Technology Research and Development Institute, Daelim Industrial, Jongno-Gu, Seoul 03152, Korea; \\ archi0528@daum.net \\ * Correspondence: ninga777@naver.com; Tel.: +82-10-3433-8213
}

Received: 9 October 2019; Accepted: 6 November 2019; Published: 7 November 2019

\begin{abstract}
The effects or high $\mathrm{CaO}$ fly ash and sulfate activator on cementless grouting material were investigated through Labiles Waterglass (LW) grouting applied at an actual construction field. Circulating fluidized bed combustion ash was used as $\mathrm{CaO}$ fly ash, and petro cokes desulfurization gypsum was used as sulfate activator. Cementless grouting material (CGM) could decrease the gel time by about $16.7 \%$ compared with ordinary Portland cement (OPC). This characteristic improved the average daily workload and construction period per meter by about $13.5 \%$ with CGM. Furthermore, when constructing 1000 holes of LW grouting, the construction time could be reduced by 19 days ( $20 \%$ of the total construction period of LW grouting). Meanwhile, CGM could increase the homogel strength by about $48.4 \%$ after 28 days compared with OPC. After X-ray diffraction analysis and scanning electron microscope analysis, CGM was found to produce cement hydrate by chemical reaction mechanism of high $\mathrm{CaO}$ fly ash and sulfate activator, even though cement was not used. The matrix structure properties of CGM and OPC specimens were similar, but CGM, with $134.3 \%$ fineness, exhibited higher compressive strength and lower air permeability than OPC. As a result, CGM could reduce the leakage length per square meter by $74.4 \%$ compared with OPC. Using CGM as a substitute for OPC in LW grouting in actual sites could be beneficial in terms of securing construction speed and durability, as well as reducing $\mathrm{CO}_{2}$ emissions due to reduction of OPC usage.
\end{abstract}

Keywords: $\mathrm{CaO}$ fly ash; sulfate activator; circulating fluidized bed combustion ash; petro cokes desulfurization gypsum; ground granulated blast-furnace slag; cementless grouting material

\section{Introduction}

The Labiles Waterglass (LW) grouting method is a type of chemical injection method developed to increase water resistance and strengthen grounds by mixing sodium silicate number 3 (SS (No. 3)) solution (liquid A) and ordinary Portland cement (OPC) suspension (liquid B). This method is widely used in Korea, because it enables high strength of consolidation and low permeability at low construction cost [1-3].

However, the manufacture of OPC involves a large amount of carbon dioxide $\left(\mathrm{CO}_{2}\right)$ emissions, which is the leading cause of the greenhouse effect in the Earth's atmosphere [4]. In 2008, $\mathrm{CO}_{2}$ emissions in the construction industry were estimated to be about $10 \%$ of the total 660 million tons of domestic $\mathrm{CO}_{2}$ generated in the reinforced concrete industry [5,6]. Among them, $\mathrm{CO}_{2}$ emissions generated by concrete was about 54 million tons, which is about eight times higher than that of rebars $[7,8]$.

To solve the problem of $\mathrm{CO}_{2}$ generation, research on geopolymer materials as a substitute for OPC in the concrete industry has been actively conducted [9-11]. In particular, the use of admixture materials that can significantly reduce cement clinker production is effective for reducing $\mathrm{CO}_{2}$ emissions, because most of the $\mathrm{CO}_{2}$ emission generated during the manufacturing process of construction materials are known to occur during cement manufacturing [12-14]. However, they are rarely applied in the 
actual field because of the slow strength development and rapid setting properties, owing to strong alkali [15-17].

Recently, studies on circulating fluidized bed combustion (CFBC) ash have been actively conducted. The chemical composition and characteristics of CFBC ash differ from those of pulverized coal combustion (PCC) ash, which can be attributed to the pulverized coal combustion methods employed in a conventional thermal power plant [18-20]. For CFBC ash, the content of free $\mathrm{CaO}$ is high and it comprises irregular particles. Thus, it exhibits hydraulic reactivity similar to OPC. On the physical side, as shown in Figure 1, PCC ash is spherical, whereas CFBC ash is irregular and rough [21-24]. These micrographs of PCC ash and CFBC ash were obtained using the Genesis-2020 scanning electron microscope (Emcrafts, Gwangju-si, Korea).

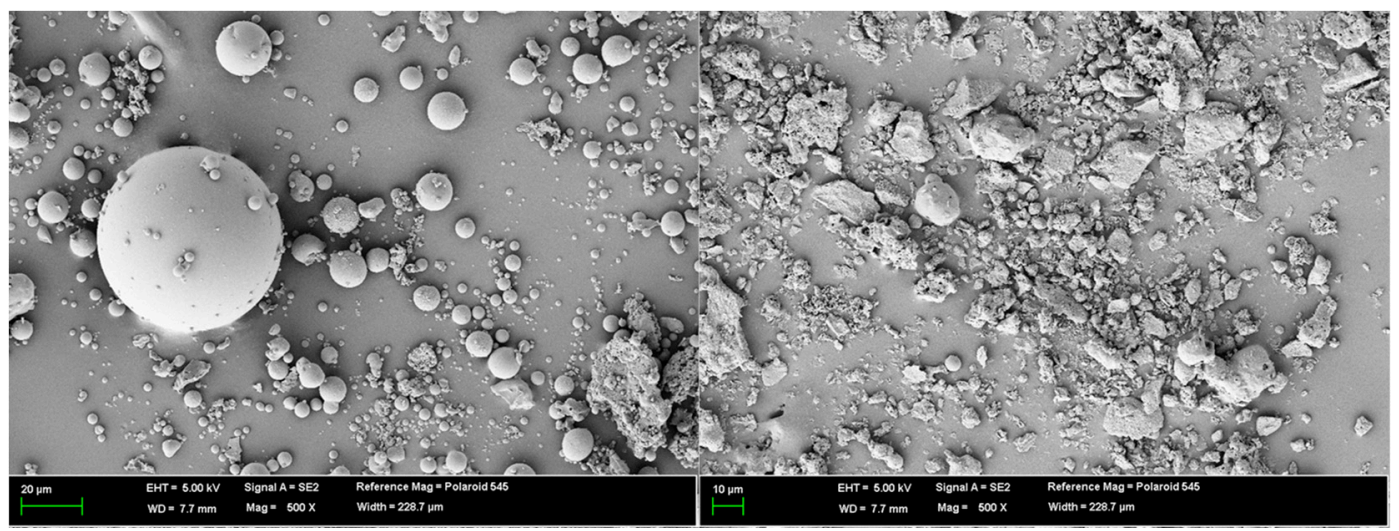

(a)

(b)

Figure 1. Scanning electron microscope of (a) pulverized coal combustion (PCC) ash and (b) circulating fluidized bed combustion (CFBC) ash.

On the other hand, in our previous study, we reviewed the engineering properties of cementless grouting material (CGM) that can replace the OPC, an existing binder type of the LW grouting method. There, we reported, the optimal conditions required for CGM, such as the binder type, water/binder (W/B) ratio, and the replacement ratio of Liquid B. CGM is a cement-based grouting inorganic powder (fineness $4190 \mathrm{~cm}^{2} / \mathrm{g}$ ) material blended with $50-60 \%$ ground granulated blast-furnace slag (GGBS), $30-40 \%$ CFBC ash, and 0-20\% petro cokes desulfurization gypsum (PCDG) [25]. CFBC ash is a high-calcium fly ash that has a self-hydration property that reacts directly with water and acts as an alkali-activator to stimulate GGBS. PCDG also acts as a sulfate activator, and this chemical reaction mechanism is summarized in Figure 2 [26,27].

However, thus far, no study has attempted to investigate the use of CFBC ash as a substitute for OPC in grouting methods. Furthermore, there have been no papers analyzing the performance and effectiveness of cementless grouting materials using high $\mathrm{CaO}$ fly ash and sulfate activator at an actual construction site.

Therefore, this study aims to evaluate the engineering characteristics (gel time, homogel strength, and constructability) and construction management aspects (cost management, schedule management, and quality management) of cementless grouting material (CGM) using CFBC ash by applying it to LW grouting at general construction sites. In this manner, CGM was applied to an actual field, and its contribution to $\mathrm{CO}_{2}$ reduction was evaluated. 


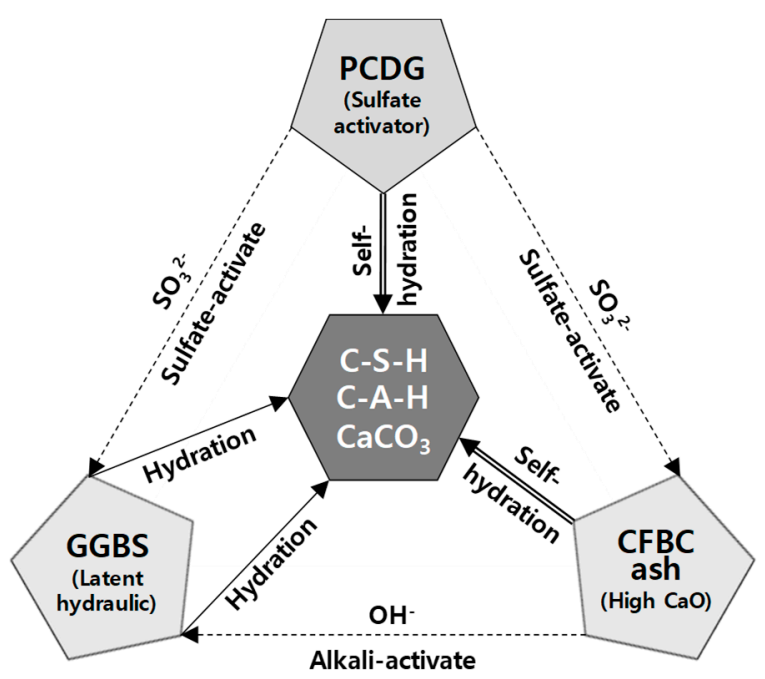

Figure 2. Chemical reaction mechanism of CGM. PCDG, petro cokes desulfurization gypsum; GGBS, ground granulated blast-furnace slag; CFBC, circulating fluidized bed combustion.

\section{Experimental Procedure}

\subsection{Materials}

Table 1 lists the physical and chemical properties of SS (No.3) applied as chemical solution of liquid $\mathrm{A}$, comprising $\mathrm{H}_{2} \mathrm{O}, \mathrm{SiO}_{2}$, and $\mathrm{Na}_{2} \mathrm{O}$. The density was $1.384 \mathrm{~g} / \mathrm{cm}^{3}$, which is slightly heavier than water. The $\mathrm{pH}$ of the solution was 14 (strong alkaline property) and its viscosity was 200 cps.

Table 1. Chemical composition and physical properties of chemical liquids used.

\begin{tabular}{|c|c|c|c|c|c|c|c|c|}
\hline \multirow{2}{*}{ Materials } & \multicolumn{5}{|c|}{ Chemical Composition (\%) } & \multirow{2}{*}{$\operatorname{Density}\left(\mathrm{g} / \mathrm{cm}^{3}\right)$} & \multirow{2}{*}{$\mathrm{pH}\left(\right.$ at $\left.25^{\circ} \mathrm{C}\right)$} & \multirow{2}{*}{ Viscosity (at $\left.25^{\circ} \mathrm{C}, \mathrm{Pa} \cdot \mathrm{s}\right)$} \\
\hline & $\mathrm{H}_{2} \mathrm{O}$ & $\mathrm{SiO}_{2}$ & $\mathrm{Na}_{2} \mathrm{O}$ & $\mathrm{Fe}_{2} \mathrm{O}_{3}$ & $W I^{(1)}$ & & & \\
\hline SS (No. 3) & 63.6 & 27.2 & 9.14 & 0.0034 & 0.0026 & 1.384 & 14 & 0.2 \\
\hline
\end{tabular}

Table 2 lists the physical and chemical properties of OPC and CGM applied as binder liquid B. CGM is an inorganic binder in which GGBS, CFBC ash, and PCDG are mixed in advance. It has high $\mathrm{SO}_{3}$ content and fineness as compared to OPC [28].

Table 2. Chemical composition and physical properties of binders used. OPC, ordinary Portland cement; CGM, cementless grouting material.

\begin{tabular}{|c|c|c|c|c|c|c|c|c|c|}
\hline \multirow{2}{*}{ Materials } & \multicolumn{7}{|c|}{ Chemical Composition (\%) } & \multirow{2}{*}{$\begin{array}{l}\text { Density } \\
\left(\mathrm{g} / \mathrm{cm}^{3}\right)\end{array}$} & \multirow{2}{*}{$\begin{array}{l}\text { Fineness } \\
\left(\mathrm{cm}^{2} / \mathrm{g}\right)\end{array}$} \\
\hline & $\mathrm{SiO}_{2}$ & $\mathrm{Al}_{2} \mathrm{O}_{3}$ & $\mathrm{Fe}_{2} \mathrm{O}_{3}$ & $\mathrm{CaO}$ & $\mathrm{MgO}$ & $\mathrm{SO}_{3}$ & Other & & \\
\hline OPC & 17.20 & 4.38 & 3.13 & 66.70 & 3.03 & 3.48 & 2.08 & 3.15 & 3,120 \\
\hline CGM & 17.60 & 7.01 & 0.52 & 58.85 & 2.02 & 12.73 & 1.27 & 2.89 & 4,190 \\
\hline
\end{tabular}

\subsection{Procedure}

Table 3 summarizes the experimental plan of this study. Liquid binders with a fraction of the mixture were set to two levels, and the rest were set to the same level. Here, the W/B ratio of liquid B was set at $140 \%$, and the volume replacement ratio of liquid B was set at $50 \%$. 
Table 3. Experimental plan. W/B, water/binder.

\begin{tabular}{|c|c|c|c|}
\hline \multicolumn{3}{|c|}{ Evaluation Items } & Experimental Variables \\
\hline \multirow{4}{*}{ Factors of mixture } & \multicolumn{2}{|c|}{ Types of liquid chemical } & SS (No. 3) \\
\hline & \multicolumn{2}{|c|}{ Types of liquid B binders } & OPC, CGM \\
\hline & \multicolumn{2}{|c|}{$\mathrm{W} / \mathrm{B}$ ratio of liquid $\mathrm{B}$} & $140 \%$ \\
\hline & \multicolumn{2}{|c|}{ Volume replacement ratio of liquid B } & $50 \%$ \\
\hline \multirow{9}{*}{ Test items } & \multirow{3}{*}{$\begin{array}{l}\text { Effects of CGM on } \\
\text { shortening gel time }\end{array}$} & Gel state & Gel time (s) \\
\hline & & Constructability & Average daily workload (m/day) \\
\hline & & Construction speed & Construction period per $1 \mathrm{~m}(\mathrm{~min} / \mathrm{m})$ \\
\hline & \multirow{6}{*}{$\begin{array}{c}\text { Effects of CGM on } \\
\text { increasing on homogel } \\
\text { strength }\end{array}$} & Hardened state & Homogel strength (MPa) \\
\hline & & \multirow{4}{*}{ Durability } & Chemical shrinkage (\%) \\
\hline & & & Air permeability $\left(\times 10^{-10} \mathrm{~m}^{2}\right)$ \\
\hline & & & $\mathrm{X}$-ray diffraction analysis \\
\hline & & & Scanning electron microscope analysis \\
\hline & & Leakage length & Leakage length per $1 \mathrm{~m}^{2}\left(\mathrm{~m} / \mathrm{m}^{2}\right)$ \\
\hline
\end{tabular}

The gel state, constructability, and construction speed of the test items were measured to analyze the effects of CGM on shortening gel time. Regarding examining the effects of CGM on increasing homogel strength, hardened state, durability, and leakage length were evaluated.

Table 4 lists the mixture proportions of the LW grouting materials used in the field application. For liquid A, $25 \mathrm{dm}^{3}$ of SS (No.3) and $25 \mathrm{dm}^{3}$ of water were mixed together, and for liquid B, $25 \mathrm{dm}^{3}$ of the binder (OPC, CGM) and $25 \mathrm{dm}^{3}$ of water were mixed together. The injection pressure of $\mathrm{LW}$ grouting was $0.3-0.7 \mathrm{MPa}$, and the materials were injected in 1.5 shots with a double-packer.

Table 4. Mixture proportions of Labiles Waterglass (LW) grouting materials.

\begin{tabular}{ccccc}
\hline \multirow{2}{*}{ Mix No. } & \multicolumn{2}{c}{ Liquid A } & \multicolumn{2}{c}{ Liquid B } \\
\cline { 2 - 5 } & SS (No.3) $\left.\mathbf{( d m}^{\mathbf{3}}\right)$ & Water $\mathbf{( \mathbf { d m } ^ { 3 } )}$ & Binders $\mathbf{( \mathbf { d m } ^ { \mathbf { 3 } } )}$ & Water $\mathbf{( \mathbf { d m } ^ { \mathbf { 3 } } )}$ \\
\hline OPC & 25 & 25 & 10 & 40 \\
\hline CGM & 25 & 25 & 10 & 40 \\
\hline
\end{tabular}

Table 5 summarizes the introduction of the project for field application to a new construction site for a knowledge industry center. The underground floors were constructed based on a steel framed reinforced concrete (SRC) structure, and the ground floors based on a reinforced concrete (RC) structure. The land area was approximately $19,486.00 \mathrm{~m}^{2}$; construction area, approximately $11,682.09 \mathrm{~m}^{2}$; total floor area, 165,153.58 $\mathrm{m}^{2}$; and total floor ratio, $445.3 \%$. Furthermore, each building had 938 rooms in 4 basement floors and 10 floors on the ground, and the construction period was 26 months.

Table 6 lists the serial number of H-piles and the sum of cross-sectional area for each OPC and CGM zone. The OPC zone comprises a total of $206 \mathrm{H}$-piles and a total cross-sectional area of about $6887 \mathrm{~m}^{2}$. In addition, the CGM zone comprises a total of $173 \mathrm{H}$-piles and a total cross-sectional area of about $6321 \mathrm{~m}^{2}$. The construction section of OPC and CGM is shown in Figure 3. 
Table 5. Introduction of project for field application.

\begin{tabular}{|c|c|}
\hline Items & Contents \\
\hline Project name & Knowledge industry center new construction \\
\hline Structure system & $\begin{array}{l}\text { Under ground floor: steel framed reinforced concrete } \\
\text { (SRC) structure; ground floor: reinforced concrete } \\
\text { (RC) structure }\end{array}$ \\
\hline Land area & $19,486.00 \mathrm{~m}^{2}$ (5894.52 pyeong) \\
\hline Construction area & $11,682.09 \mathrm{~m}^{2}$ (3533.83 pyeong) \\
\hline Total floor area & $165,153.58 \mathrm{~m}^{2}(49,958.96$ pyeong $)$ \\
\hline Total floor ratio & $445.30 \%$ \\
\hline Building scale & $\begin{array}{l}4 \text { basement floors }-10 \text { floors/ } 1 \text { building/total } \\
\text { of } 938 \text { rooms }\end{array}$ \\
\hline Work period & 26 months \\
\hline
\end{tabular}

Table 6. LW grouting sections by binder types.

\begin{tabular}{ccc}
\hline Binder Types & Serial Number of H-Pile & Sum of Cross Section Area \\
\hline OPC & $1-196,370-379$ & $6887 \mathrm{~m}^{2}$ \\
\hline CGM & $197-369$ & $6321 \mathrm{~m}^{2}$ \\
\hline
\end{tabular}

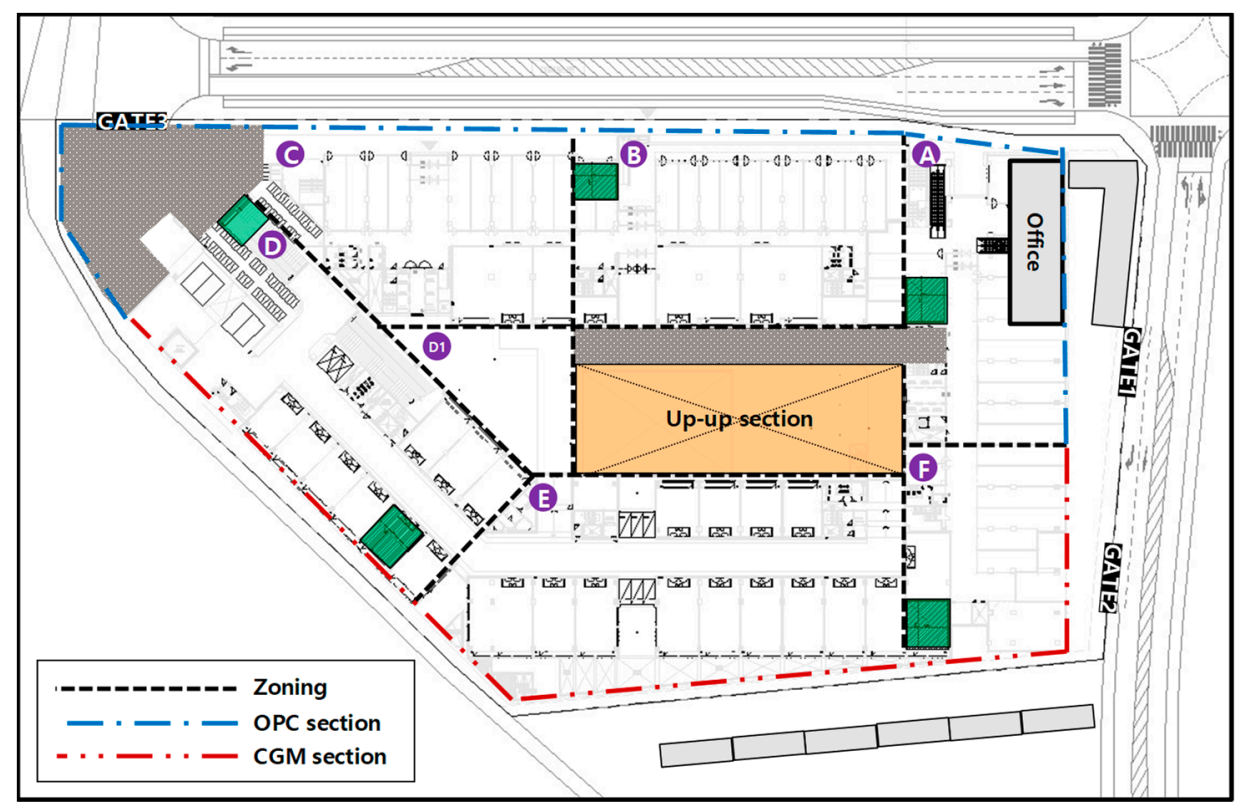

Figure 3. Construction section of OPC and CGM.

\subsection{Test Methods}

\subsubsection{Gel Time}

The gel time is a major property indicating the characteristics of CGM. When liquids A and B are mixed, the viscosity of the mixture gradually increases, and finally, the fluidity is lost and gelation proceeds. The gel time refers to the time required from the mixing of CGM to the loss of fluidity and start of gelation [29]. 
The gel time can be measured using two methods: Cup mixing and viscometer methods. In this study, the viscometer method was used for indoor tests, and the cup mixing method was used for the field test [30].

The cup mixing method is described as follows. First, $50 \mathrm{~mL}$ of liquids A and B were measured in a beaker or paper cup. Thereafter, the entire amount of liquid B was mixed with liquid A at intervals of about $1 \mathrm{~s}$, and the entire liquid $\mathrm{A}$ was mixed with liquid $\mathrm{B}$.

When liquid A and liquid B were continuously stirred, the fluidity was rapidly lost. The time at which the flow of the mixed solution stops was recorded as the gel time, which was measured three times for each type of mixture proportion, and the average value (rounded off at the first decimal place) was calculated.

In addition, the target of gel time was set at $20-50$ s by referring to the LW grouting method special specification of Jeong-sun engineering company [31].

\subsubsection{Homogel Strength}

Figure 4 shows the methods of the homogel strength test. Cubic specimens of $50 \mathrm{~mm} \times 50 \mathrm{~mm} \times 50 \mathrm{~mm}$ were produced according to ASTM C109/C109M: 16a (Standard Test Method for Compressive Strength of Hydraulic Cement Mortars) [32]. Specimens were cured in the mold for $24 \mathrm{~h}$; after re-molding, they were cured in a water tank at a curing temperature of $20 \pm 2{ }^{\circ} \mathrm{C}$, as per the ASTM C109/C109M. After the 7th day of aging, the mean values of three specimens were calculated for each mixing factor.

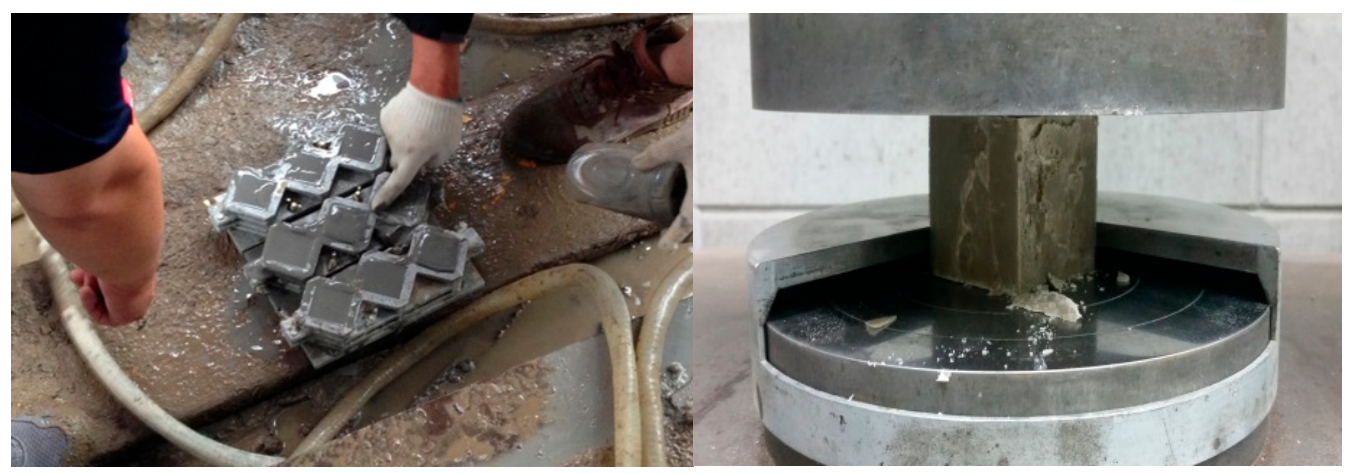

(a)

(b)

Figure 4. Test methods of homogel strength: (a) Molding of cubic molds for homogel strength test;

(b) homogel strength test.

The homogel strength is the main property of the grouting material, indicating the compressive strength of the cementitious material obtained by curing solely the mixture of liquids A and B. Therefore, the homogel strength was evaluated by the compressive strength at the initial age of 7 days to determine the progress of the cementation of the grouting material. Generally, the goal is to achieve a homogel strength of at least $2 \mathrm{MPa}$ at 7 days in the construction site.

\subsubsection{Chemical Shrinkage and Air Permeability}

Figure 5 a shows the indoor air permeability coefficient test method used in this study. To determine the air permeability coefficients of OPC and CGM, specimens were prepared by cutting cylindrical shapes in a size of $\varnothing 100 \mathrm{~mm} \times 200 \mathrm{~mm}$ to $50 \mathrm{~mm}$ from the center of the compounds at the age of 2 and 4 weeks. These specimens were tested in accordance with KS L 3317, Testing Method for Permeability to Gases of Refractory Products [33]. The air permeability coefficient of specimens was calculated based on Equation (1), and the air permeability coefficient was determined as the average of three specimens. 
Also, Figure $5 \mathrm{~b}$ shows the results of the chemical shrinkage test by age, conducted in accordance with ASTM C 1608 [34].

$$
\mu=c \times \eta \times \frac{h}{3.14\left(\frac{d}{2}\right)^{2}} \times \frac{1}{p_{1}} \times\left(\frac{2\left(p_{0}+p_{1}\right)}{2 p_{0}+p_{1}}\right) \times q_{v}
$$

where, $\mu$ : air permeability coefficient of specimen $\left(\mathrm{m}^{2}\right)$

c: correction factor $\left(1 / 60 \times 10^{-6}\right)$

$\eta$ : viscosity of measured gas (Pa.s)

$h$ : height of specimen (mm)

$d$ : diameter of specimen (mm)

$p_{0}$ : atmospheric pressure $(\mathrm{kPa})$

$p_{1}$ : gas pressure $(\mathrm{kPa})$

$q_{v}$ : gas flow rate $\left(\mathrm{cm}^{3} / \mathrm{min}\right)$.

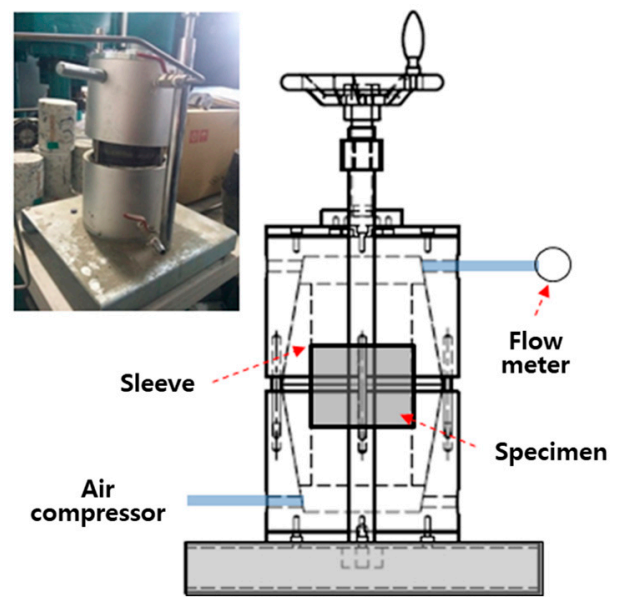

(a)

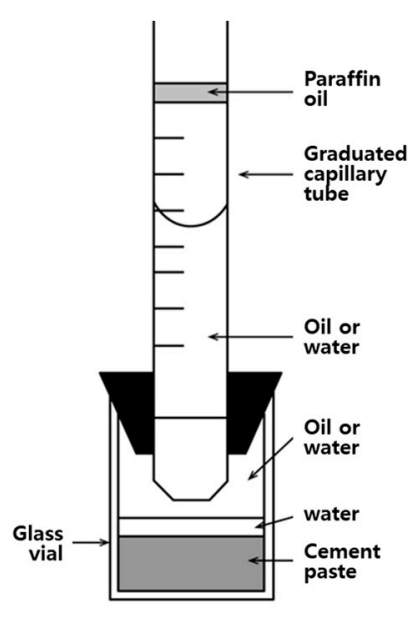

(b)

Figure 5. Test methods of (a) the air permeability test and (b) the chemical shrinkage test.

\subsubsection{Other Test Items}

To evaluate the constructability and construction speed, the average daily workload and construction period per meter of the OPC and CGM sections was calculated. For examining durability, X-ray diffraction analysis and scanning electron microscope analysis were performed. Further, leakage length per square meter were measured to assess the leakage length. The protocol for the assessment of the leakage was conducted as follows: Visual observation and recording of the leakage length after rain, followed by calculation of the total construction area of LW grouting wall and calculation of the leakage length per square meter.

\section{Results and Discussion}

\subsection{Effects of CGM on Shortening Gel Time}

Figure 6 shows the measurement results of gel time for binder type of liquid $\mathrm{B}$. The gel time average of OPC was found to be $42 \mathrm{~s}$, whereas that of CGM was $35 \mathrm{~s}$. Both OPC and CGM satisfied the target range of gel time (20 50 s). Thus, under the same mixture proportions and field conditions, CGM shortened the gel time by $7 \mathrm{~s}$ after 7 days, compared with OPC. This is because the fineness of CGM $\left(4190 \mathrm{~cm}^{2} / \mathrm{g}\right)$ is $134.3 \%$ higher than that of OPC $\left(3120 \mathrm{~cm}^{2} / \mathrm{g}\right)$, and the reaction time with SS 
(No.3) is accelerated and gel time is shortened. Figure 7 shows the comparison of field (this paper) and indoor [25] test results of gel time according to binder weight, with similar results.

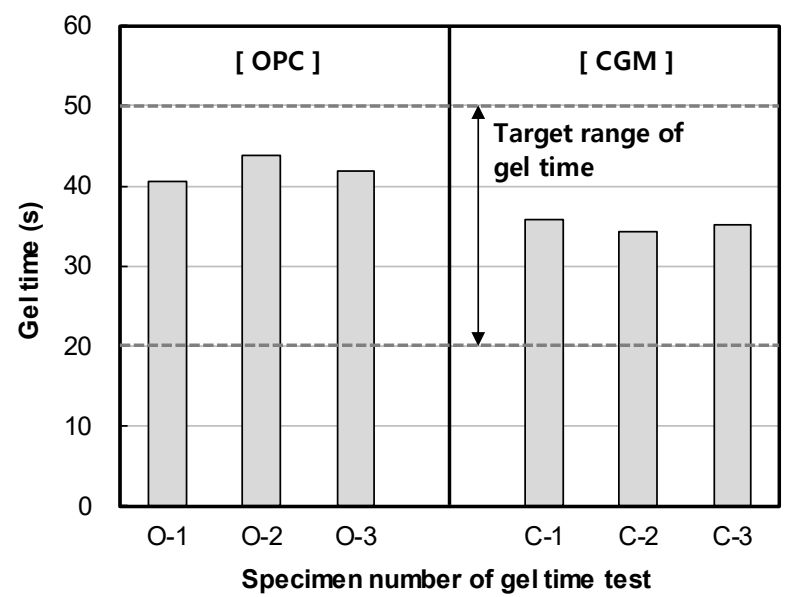

Figure 6. Measurement results of gel time of OPC and CGM.

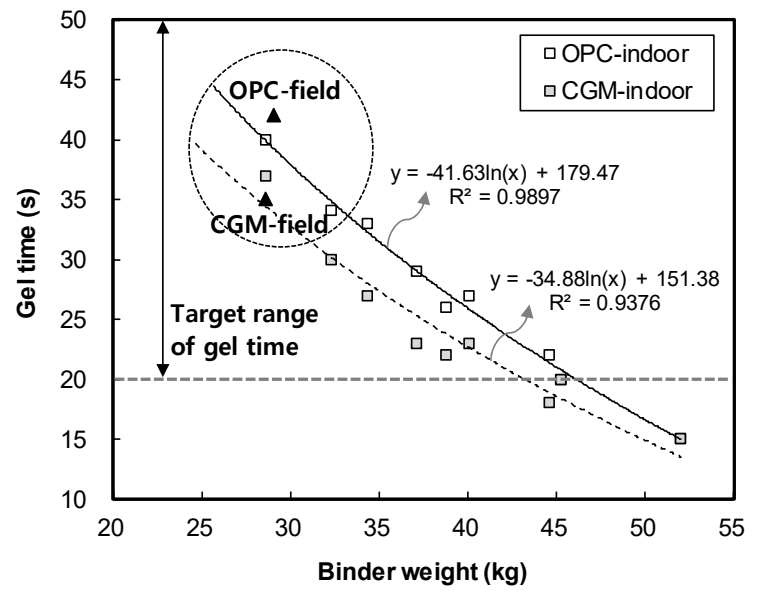

Figure 7. Comparison of field and indoor test results of gel time according to binder weight.

With the application of CGM to the construction site, the grouting step injection could be sped up by shortening the gel time. Table 7 summarizes the results of measuring the average daily workload by binder type liquid B. Using OPC, 95 days were required for constructing a total length of 13,913 m, and the average daily workload was measured as $146.5 \mathrm{~m} /$ day. With CGM, 76 days were required for constructing a total length of $12,642 \mathrm{~m}$, and the average daily workload was measured as $166.3 \mathrm{~m} /$ day. Thus, the average daily workload of CGM was higher by $19.8 \mathrm{~m} /$ day than that of OPC. The measurement of average daily workload was based on $8 \mathrm{~h} /$ day (one machine, two workers) of working time.

Table 7. Results of measuring the average daily workload.

\begin{tabular}{ccccc}
\hline Items & Total Length(m) & $\begin{array}{c}\text { Work Days } \\
\text { (Days) }\end{array}$ & $\begin{array}{c}\text { Average Daily Workload } \\
\text { (m/Day) }\end{array}$ & Remarks \\
\hline OPC & 13,913 & 95 & 146.5 & $\begin{array}{c}\text { Measured based on } 8 \mathrm{~h} / \text { day } \\
\text { (one machine, two workers) }\end{array}$ \\
\hline CGM & 12,642 & 76 & 166.3 & .
\end{tabular}

The main factor affecting the average daily workload was gel time, under the same conditions of OPC and CGM in the field. This is because the grouting step injection rate becomes faster as the gel time is increased, as described above. Figure 8 shows the relationship between gel time and workload, 
which was derived with the function formula $y=-2.8286 x+265.3$. CGM reduced the gel time by about $16.7 \%$ after 7 days, and the constructability was improved by about $13.5 \%$.

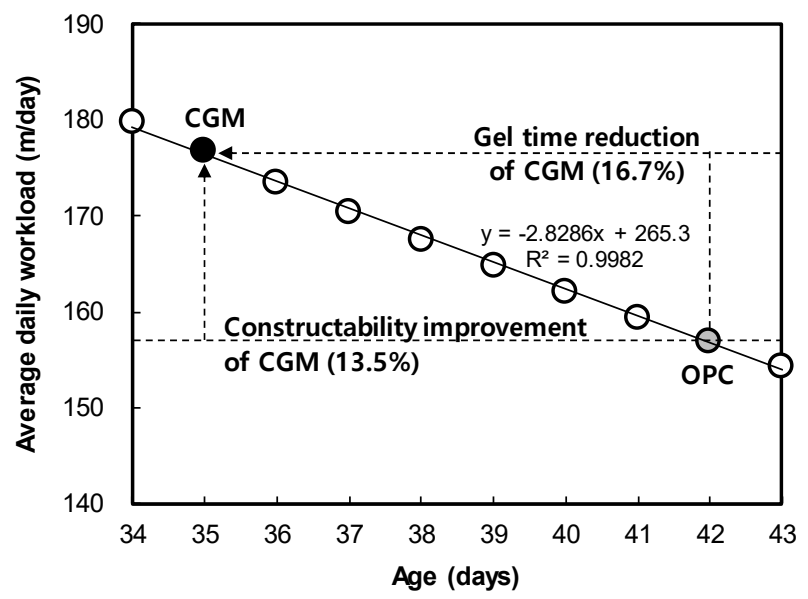

Figure 8. Correlation between gel time and average daily workload.

Meanwhile, Table 8 summarizes the analyzed results of the construction period per meter by binder type of liquid B. For OPC, a total construction period of 45,600 min was required for the total length $13,913 \mathrm{~m}$, and the construction period per meter was calculated as $3.28 \mathrm{~min}$. For CGM, a total construction period of $36,480 \mathrm{~min}$ was required for the total length $12,642 \mathrm{~m}$, and the construction period per meter was calculated as $2.89 \mathrm{~min}$.

Table 8. Results of measuring construction period per meter.

\begin{tabular}{|c|c|c|c|c|}
\hline Items & Total Length (m) & $\begin{array}{l}\text { Construction } \\
\text { Period (min) }\end{array}$ & $\begin{array}{c}\text { Construction } \\
\text { Period Per Meter }(\mathrm{min} / \mathrm{m})\end{array}$ & Remarks \\
\hline OPC & 13,913 & 45,600 & 3.28 & \multirow{2}{*}{$\begin{array}{l}\text { Measured based on } 8 \mathrm{~h} / \text { day } \\
\text { (one machine, two workers) }\end{array}$} \\
\hline CGM & 12,642 & 36,480 & 2.89 & \\
\hline
\end{tabular}

Thus, the construction period of CGM per meter is shorter by 0.38 min compared with OPC. The construction period per meter was calculated based on $8 \mathrm{~h}$ /day (one machine, two workers) of working time.

To analyze the construction speeds of OPC and CGM, this study analyzed the construction procedure in terms of unit work and measured the average work time per unit work. The results are shown in Figure 9. The injection speed of CGM, which has high fineness, was evaluated to be faster than that of OPC, and the construction speed for one hole ( $23 \mathrm{~m}$ depth) was faster by $113.5 \%$. Thus, when constructing 1000 holes, CGM can shorten the construction time by approximately 19 days compared with OPC (based on $8 \mathrm{~h} /$ day).

The results of analyzing the effects of CGM on shortening gel time are as follows: CGM has been shown to reduce the gel time, compared to OPC, by about $16.7 \%$. In the actual field, it was analyzed that constructability (average daily workload) and construction speed (construction period per meter) improved by about $13.5 \%$ when applying CGM to LW grouting. As a result, when constructing 1000 holes of LW grouting, the construction time could be reduced by 19 days $(20 \%$ of the total construction period of LW grouting). 


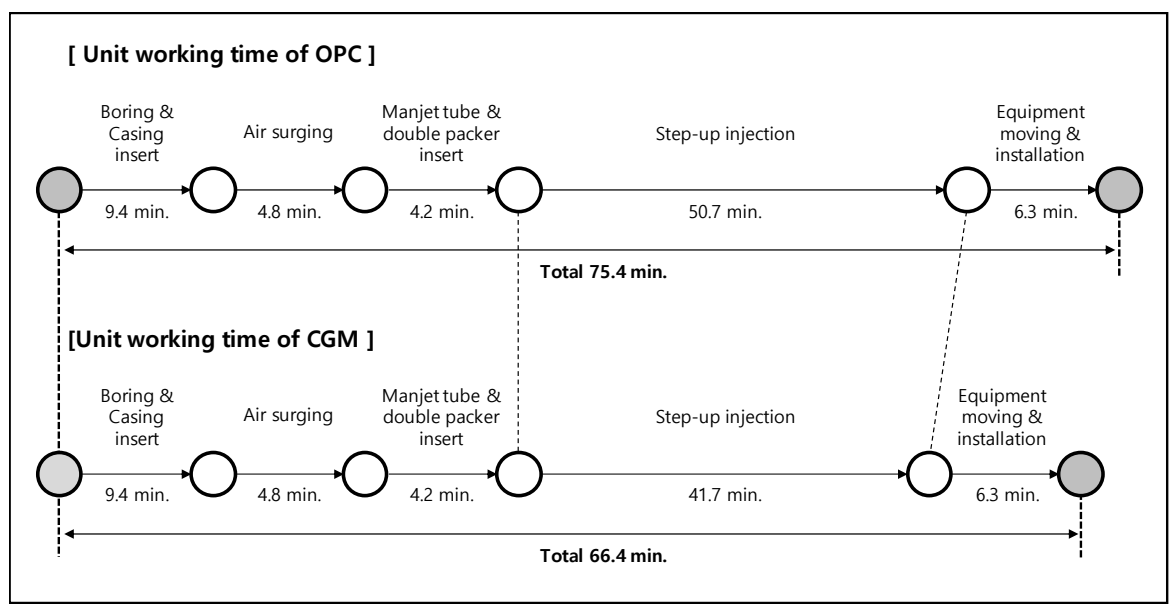

Figure 9. Unit work speed analysis results of OPC and CGM.

\subsection{Effects of CGM on Increasing Homogel Strength}

Figure 10 shows the measurement results of homogel strength for binder type liquid $\mathrm{B}$. The gel time and homogel strength of OPC was found to be $4.5 \mathrm{MPa}$, whereas that of CGM was 6.0 MPa after 7 days. Both OPC and CGM satisfied the target range of homogel strength (2.0 MPa or more at 7 days). Thus, under the same mixture proportions and field conditions, CGM increased the homogel strength by $3.1 \mathrm{MPa}(48.4 \%)$ after 28 days, compared with OPC. Figure 11 shows the comparison of field (this paper) and indoor [25] test results of homogel strength according to binder weight, with similar results to gel time in Section 3.1.

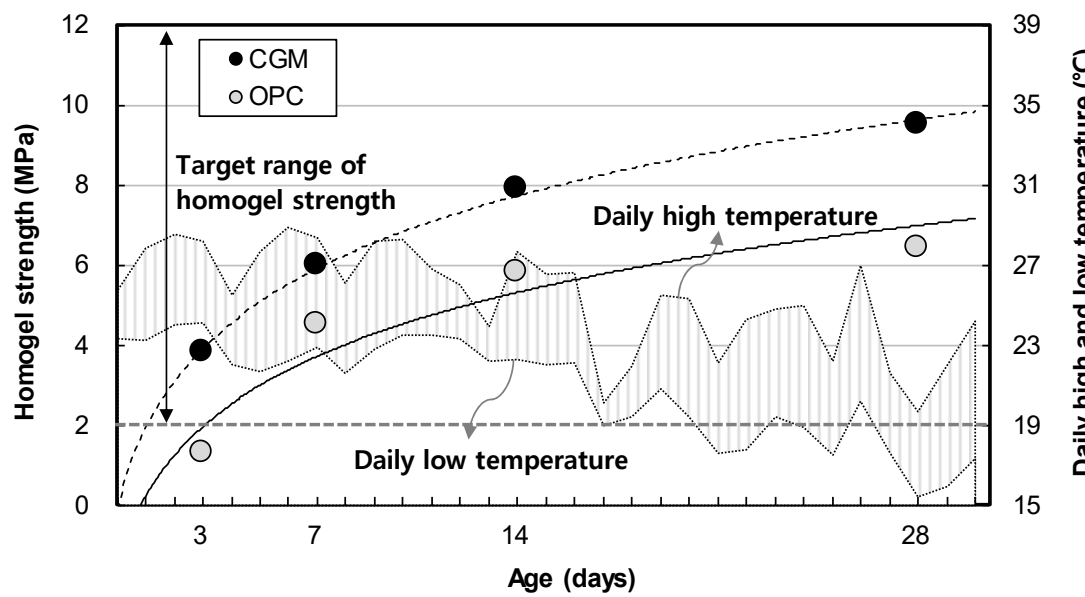

Figure 10. Measurement results of homogel strength of OPC and CGM.

With the application of CGM to the construction site, the homogel strength could be increased to improve the durability of impermeable walls, and the ability to withstand the influence of groundwater through initial strength could be improved.

Figure 12 shows the chemical shrinkage test result of OPC and CGM according to age. As a result, the chemical shrinkage of OPC was approximately $0.068 \mathrm{ml} / \mathrm{g}$ at 6 days, whereas that of CGM was approximately $0.016 \mathrm{~mL} / \mathrm{g}$ at the same age. Thus, the chemical shrinkage of CGM was smaller by approximately $23.5 \%$ compared to that of OPC. Therefore, as the chemical shrinkage of CGM is $23.5 \%$ smaller than that of OPC, it is expected to reduce the possibility of leakage compared to OPC when CGM is applied to the actual field impermeable wall. 


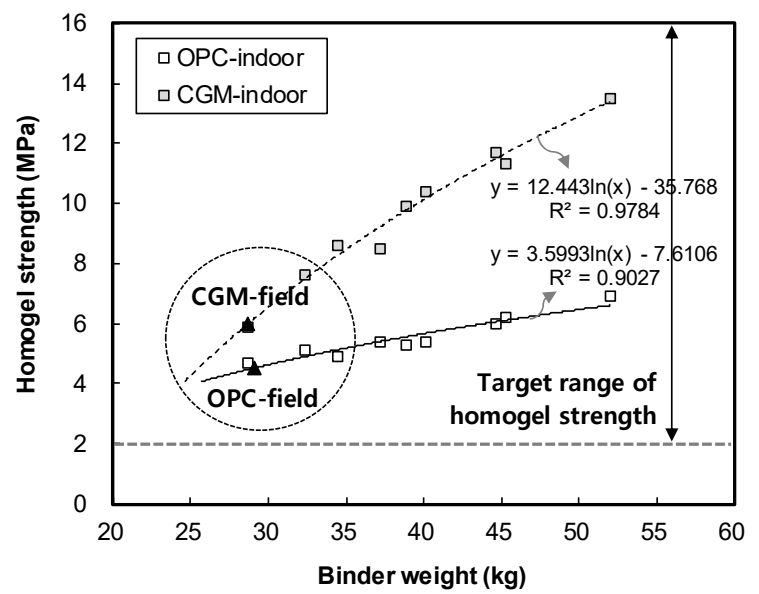

Figure 11. Comparison of field and indoor test results of homogel strength according to binder weight.

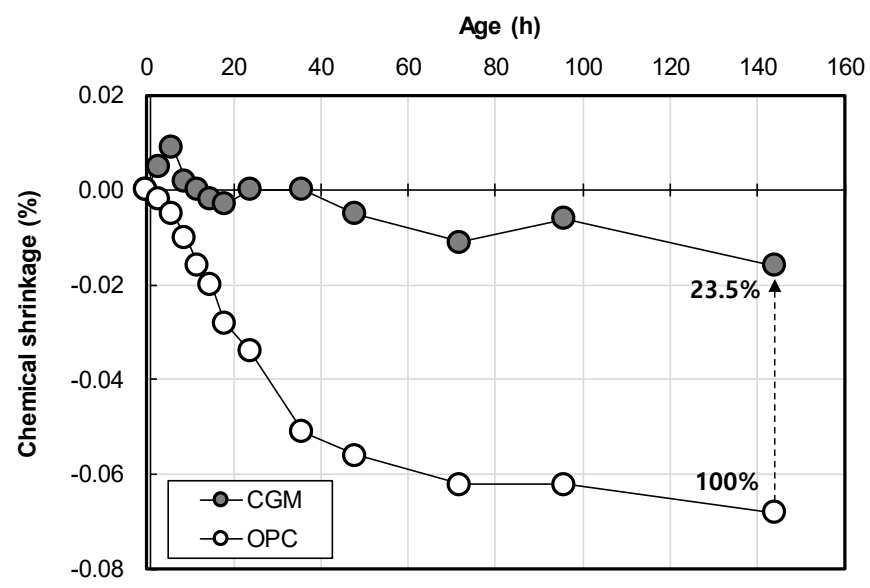

Figure 12. Chemical shrinkage test result of OPC and CGM according to age.

Figure 13 shows the indoor air permeability coefficient test result of OPC and CGM according to curing water types. In fresh water curing, air permeability of CGM was $81.9 \%$ and $23.4 \%$ at 2 and 4 weeks of age, and $83.1 \%$ and $28.2 \%$ at 2 and 4 weeks of sea water curing conditions, respectively. Therefore, CGM was judged to have excellent water tightness under the same curing conditions and excellent performance under sea water curing conditions compared to OPC. Also, Figure 14 shows the correlation between permeability and compressive strength according to age. As permeability decreased by $0.1 \times 10^{-10} \mathrm{~m}^{2}$, homogel strength increased $0.34 \mathrm{MPa}$ and $1.5 \mathrm{MPa}$ at 2 and 4 weeks of age, respectively. The trend of this graph justifies the principle that matrix structure becomes dense as the homogel strength increases. It was found that the larger the age, the greater the effect of pore amount on the homogel strength, because the air permeability coefficient tends to decrease as the age increases. In particular, homogel strength at 4 weeks of CGM was able to obtain $93 \%$ of fresh water curing conditions, even under sea water curing conditions. Therefore, in order to secure durability in the ground, it would be advantageous to apply CGM to OPC.

Figure 15 shows the $\mathrm{X}$-ray diffraction analysis results of OPC and CGM at 4 weeks of age. In the OPC specimen, calcium silicate hydrate (C-S-H), ettringite $\left(\mathrm{Ca}_{6} \mathrm{Al}_{2}\left(\mathrm{SO}_{4}\right)_{3}(\mathrm{OH})_{12} \cdot 26 \mathrm{H}_{2} \mathrm{O}\right)$, and calcite $\left(\mathrm{CaCO}_{3}\right)$ were detected, which are representative hydrates of cement at the age of 4 weeks. On the other hand, in the CGM specimen, portlandite $\left(\mathrm{Ca}(\mathrm{OH})_{2}\right)$ and quartz $\left(\mathrm{SiO}_{2}\right)$ were detected, in addition to $\mathrm{C}-\mathrm{S}-\mathrm{H}$, ettringite, and calcite. The fact that not only OPC, but also CGM generated C-S-H and ettringite, which are cement hydrates, confirms that CGM generated cement hydrates by hydration, even with no cement. This is also seen in the X-ray diffraction analysis of OPC and CGM, where no 
detectable differences are observed. The CGM specimen generated portlandite, in addition to the OPC hydrates, after aging of 4 weeks.

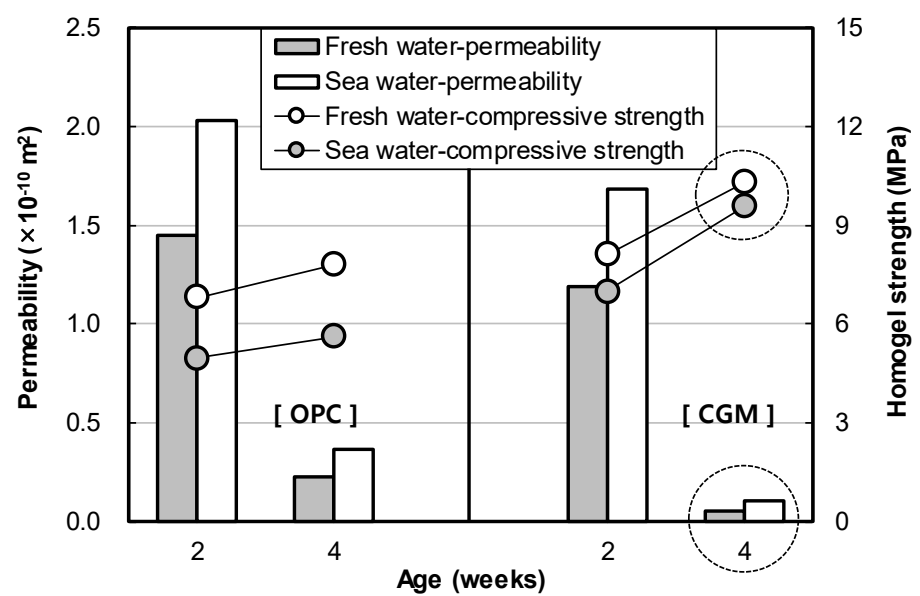

Figure 13. Indoor air permeability coefficient test result of OPC and CGM according to curing water types.

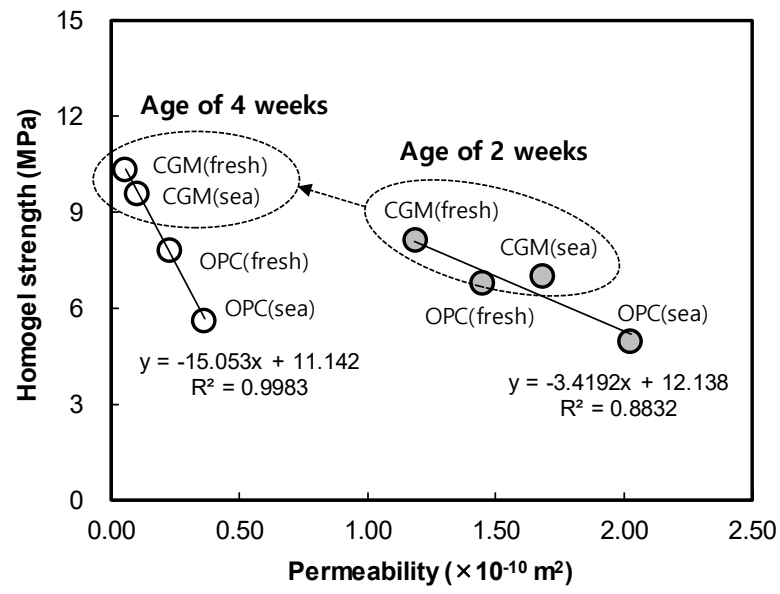

Figure 14. Correlation between permeability and compressive strength according to age.

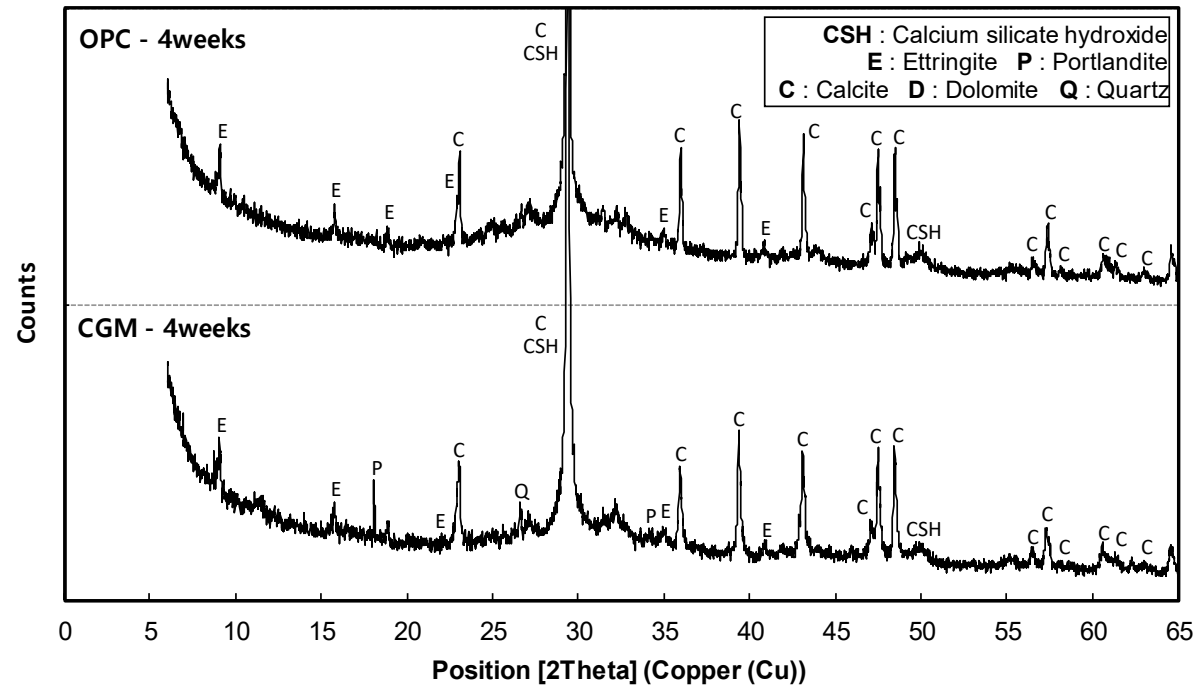

Figure 15. X-ray diffraction analysis results of OPC and CGM at 4 weeks of age. 
Figure 16 shows the scanning electron microscope analysis results of OPC and CGM aged 2 and 4 weeks. As shown in Figure 15, CGM specimens showed more portlandite $\left(\mathrm{Ca}(\mathrm{OH})_{2}\right)$ and quartz $\left(\mathrm{SiO}_{2}\right)$ than OPC. Since both CGM and OPC are composed of calcium silicate hydrate $(\mathrm{C}-\mathrm{S}-\mathrm{H})$, ettringite $\left(\mathrm{Ca}_{6} \mathrm{Al}_{2}\left(\mathrm{SO}_{4}\right)_{3}(\mathrm{OH})_{12} \cdot 26 \mathrm{H}_{2} \mathrm{O}\right)$, and calcite $\left(\mathrm{CaCO}_{3}\right)$, the matrix structure properties of $\mathrm{CGM}$ and OPC specimens were almost similar. In addition, the overall number and size of cracks were found to be almost similar. This confirmed that a hardened OPC-like matrix structure could be made using the high $\mathrm{CaO}$ fly ash and sulphate activator without using cement.

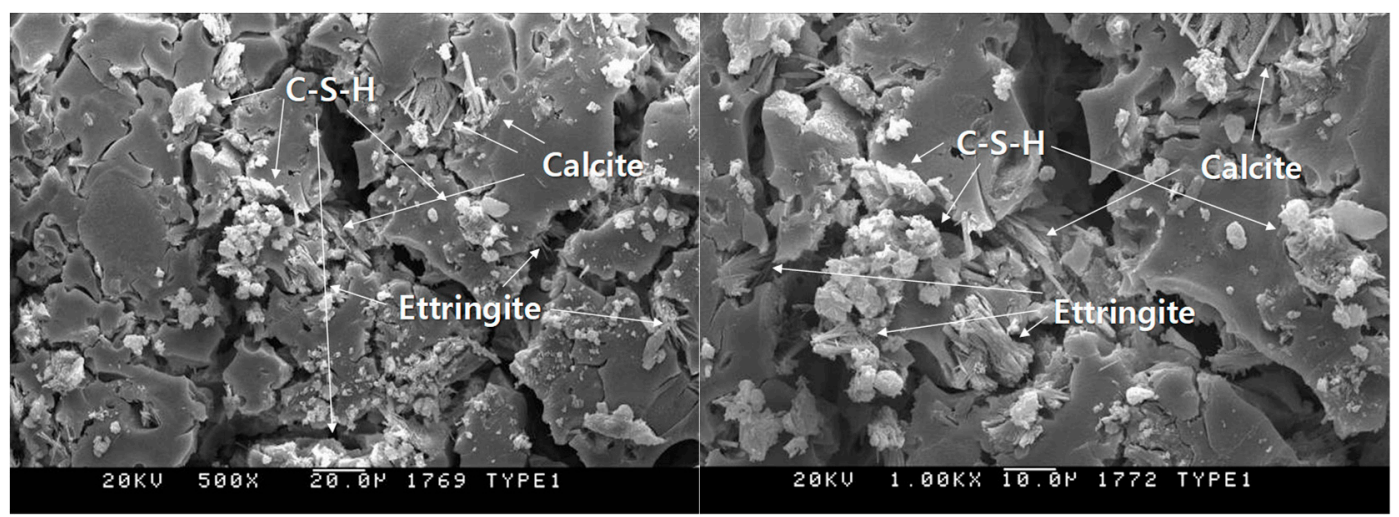

(a)

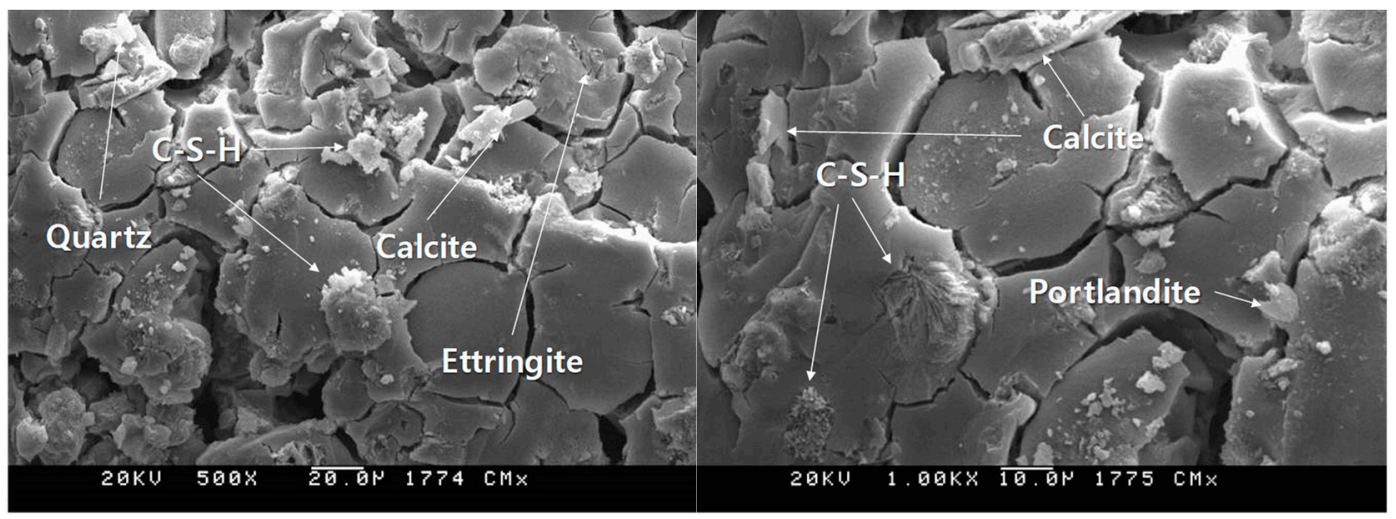

(c)

(d)

Figure 16. Scanning electron microscope analysis results of (a) OPC-500×, (b) OPC-1000×, (c) CGM-500×, and (d) CGM-1000 $\times$ at 4 weeks of age.

Table 9 summarizes the leakage length measurement results by binder type liquid B. For OPC, the total leakage length for a total area of $6887 \mathrm{~m}^{2}$ was $85 \mathrm{~m}$. Thus, the leakage length per square meter was calculated as $0.012 \mathrm{~m}$. For CGM, the total leakage length for a total area $6321 \mathrm{~m}^{2}$ was $20 \mathrm{~m}$. Thus, the leakage length per square meter was calculated as $0.003 \mathrm{~m}$. Therefore, the leakage length of CGM per $\mathrm{m}^{2}$ was shorter by $0.009 \mathrm{~m} / \mathrm{m}^{2}$ compared with OPC.

Table 9. Results of measuring leakage length per square meter.

\begin{tabular}{|c|c|c|c|c|}
\hline Items & Area $\left(\mathrm{m}^{2}\right)$ & Leakage Length (m) & $\begin{array}{l}\text { Leakage Length } \\
\text { Per } 1 \mathrm{~m}^{2}\left(\mathrm{~m} / \mathrm{m}^{2}\right)\end{array}$ & Remarks \\
\hline OPC & 6887 & 85 & 0.012 & \multirow{2}{*}{$\begin{array}{l}\text { Measured based on the } \\
\text { length of CIP leak section }\end{array}$} \\
\hline CGM & 6321 & 20 & 0.003 & \\
\hline
\end{tabular}


Figure 17 shows the leakage zone and cumulative leakage length of OPC and CGM according to the number of H-piles. The slope of cumulative leakage length of CGM was smaller than that of OPC. In addition, the total cumulative leakage length of CGM was about $65 \mathrm{~m}$ shorter than that of OPC. Figure 7 shows that the gel time of CGM was faster than that of OPC; therefore, CGM was less affected by water in the ground. Moreover, the initial compressive strength of CGM was high, which is advantageous for ensuring the durability of impermeable walls.

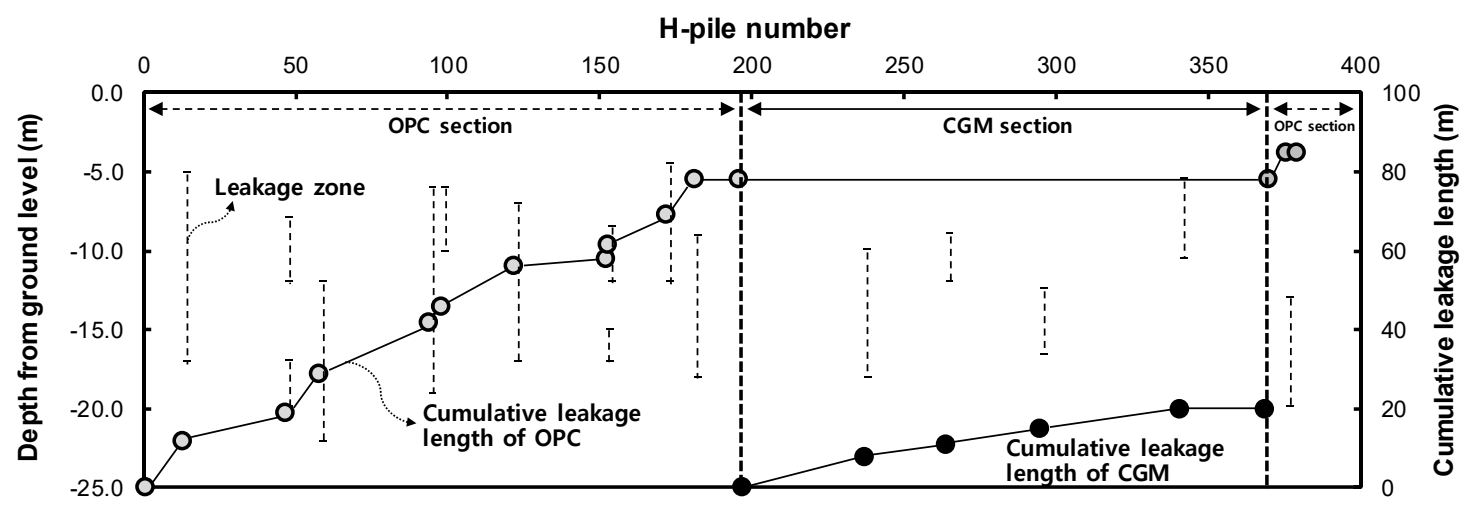

Figure 17. Leakage zone and cumulative leakage length of OPC and CGM according to the number of H-piles.

The results of analyzing the effects of CGM on increasing homogel strength are as follows: CGM has been shown to increase the homogel strength compared to OPC by about $48.4 \%$ after 28 days. From X-ray diffraction and scanning electron microscopy analysis, the matrix structure properties of CGM and OPC specimens were observed to be quite similar. This confirmed that a hardened OPC-like matrix structure could be made using the high $\mathrm{CaO}$ fly ash and sulphate activator without using cement. On the other hand, CGM showed a $48.4 \%$ increase in compressive strength compared to OPC at 28 days of age. In addition, the air permeability was $23.4 \%$ and $28.2 \%$ compared to OPC in fresh and sea water curing conditions, respectively. The reason for this seems to be that at the early age, the fineness of CGM is higher than that of OPC, implying that there are more particles within the same volume, and the structure becomes denser by the early reaction of free $\mathrm{CaO}$ whose quantity is larger in CGM. As a result, CGM could reduce the leakage length per square meter by $74.4 \%$ compared with OPC.

\section{Conclusions}

In this study, the effects or high $\mathrm{CaO}$ fly ash and sulfate activator on cementless grouting material were investigated through LW grouting applied at an actual construction field. The following conclusions can be drawn.

(1) CGM could decrease the gel time by about $16.7 \%$ compared with OPC. When CGM is applied as a binder for LW grouting in the field, the step injection speed increases, so the average daily workload and construction period per meter increase about $13.5 \%$. As a result, when constructing 1000 holes of LW grouting, the construction time could be reduced by 19 days $(20 \%$ of the total construction period of LW grouting).

(2) In addition, CGM could increase the homogel strength by about $48.4 \%$ after 28 days compared with OPC. The chemical shrinkage of CGM was smaller by approximately $23.5 \%$ at 6 days of age compared to that of OPC. Also, the air permeability of CGM was $23.4 \%$ and $28.2 \%$ of OPC at 4 weeks of age under fresh water curing and sea water curing, respectively. Therefore, CGM showed less pore structure and watertight characteristics than OPC.

(3) After X-ray diffraction analysis and scanning electron microscope analysis, CGM was found to produce cement hydrate by the chemical reaction mechanism of high $\mathrm{CaO}$ fly ash and sulfate activator, even though cement was not used. The matrix structure properties of CGM and OPC specimens were 
quite similar. However, the CGM fineness was 134.3\% higher than that of OPC, indicating that the CGM had high compressive strength and low air permeability.

Using CGM as a substitute for OPC in LW grouting in actual sites could be beneficial in terms of securing construction speed and durability, as well as reducing $\mathrm{CO}_{2}$ emissions by reducing OPC usage. Our future study will focus on understanding the reactivity properties of CGM and OPC according to chemical and mineralogical composition, the role of $\mathrm{pH}$, the activator, etc. Moreover, we will approach the environmental management aspect of the application of the LW grouting method to examine the environment-friendly characteristics of CGM for $\mathrm{CO}_{2}$ reduction and energy conservation.

Author Contributions: Conceptualization, J.L. and T.L.; investigation, J.L. and T.L.; resources, J.L.; writingoriginal-draft, J.L.; writing-review and editing, J.L. and T.L.

Funding: This research received no external funding.

Acknowledgments: This research did not receive any specific grant from funding agencies in the public, commercial, or not-for-profit sectors.

Conflicts of Interest: We declare that we have no financial and personal relationships with other people or organizations that could inappropriately influence our work.

\section{References}

1. Chun, B.; Do, J.; Sung, H.; Lim, J. A study on the reinforcement and environmental impact of LW Injection. J. Korean Geoenviron. Soc. 2006, 7, 121-131.

2. Axelsson, M.; Gustafson, G.; Fransson, A. Stop mechanism for cementitious grouts at different water-to-cement ratios. Tunn. Undergr. Space Technol. 2009, 24, 390-397. [CrossRef]

3. Lee, S.W.; Kim, T.S.; Sim, B.K.; Kim, J.S.; Lee, I.M. Effect of pressurized grouting on pullout resistance and group efficiency of compression ground anchor. Can. Geotech. J. 2012, 49, 939-953. [CrossRef]

4. Kroehong, W.; Sinsiri, T.; Jaturapitakkul, C.; Chindaprasirt, P. Effect of palm oil fuel ash fineness on the microstructure of blended cement paste. Constr. Build. Mater. 2011, 25, 4095-4104. [CrossRef]

5. Choi, D. A Fundamental Study on the Response of the Concrete Industry to Climate Change; Eco-Friendly Concrete Committee of the Korea Concrete Institute: Seoul, Korea, 2009.

6. Yi, Y.; Lu, K.; Liu, S.; Al-Tabbaa, A. Property changes of reactive magnesia-stabilized soil subjected to forced carbonation. Can. Geotech. J. 2015, 53, 314-325. [CrossRef]

7. Lee, $\mathrm{H} . \mathrm{CO}_{2}$ reduction technology for concrete. Mag. Korea Concr. Inst. 2011, 23, $28-31$.

8. Yi, Y.; Liska, M.; Unluer, C.; Al-Tabbaa, A. Carbonating magnesia for soil stabilization. Can. Geotech. J. 2013, 50, 899-905. [CrossRef]

9. Phoo-ngernkham, T.; Chindaprasirt, P.; Sata, V.; Hanjitsuwan, S.; Hatanaka, S. The effect of adding nano-SiO and nano- $\mathrm{Al}_{2} \mathrm{O}_{3}$ on properties of high calcium fly ash geopolymer cured at ambient temperature. Mater. Des. 2014, 55, 58-65. [CrossRef]

10. Guo, X.; Shi, H.; Dick, W.A. Compressive strength and microstructural characteristics of class C fly ash geopolymer. Cem. Concr. Compos. 2010, 32, 142-147. [CrossRef]

11. Kim, J.W.; Lee, K.S.; Shin, S.W. A study on the development of an assessment methodology for emission from concrete manufacturing to CIP. J. Archit. Inst. Korea Plan. Des. 2011, 27, 103-110.

12. Hu, S.; Wang, H.; Zhang, G.; Ding, Q. Bonding and abrasion resistance of geopolymeric repair material made with steel slag. Cem. Concr. Compos. 2008, 30, 239-244. [CrossRef]

13. Pacheco-Torgal, F.; Castro-Gomes, J.P.; Jalali, S. Adhesion characterization of tungsten mine waste geopolymeric binder. Influence of OPC concrete substrate surface treatment. Constr. Build. Mater. 2008, 22, 154-161. [CrossRef]

14. Woyciechowski, P.; Woliński, P.; Adamczewski, G. Prediction of carbonation progress in concrete containing calcareous fly ash co-binder. Materials 2019, 12, 2665. [CrossRef] [PubMed]

15. Motorwala, A.; Shah, V.; Kammula, R.; Nannapaneni, P.; Raijiwala, P.D.B. Alkali activated fly-ash based geopolymer concrete. Int. J. Emerg. Technol. Adv. Eng. 2013, 3, 159-166.

16. Bilim, C.; Atiş, C.D. Alkali activation of mortars containing different replacement levels of ground granulated blast furnace slag. Constr. Build. Mater. 2012, 28, 708-712. [CrossRef] 
17. Puertas, F.; Martínez-Ramírez, S.; Alonso, S.; Vazquez, T. Alkali-activated fly ash/slag cements: Strength behaviour and hydration products. Cem. Concr. Res. 2000, 30, 1625-1632. [CrossRef]

18. Chindaprasirt, P.; Rattanasak, U. Utilization of blended fluidized bed combustion (FBC) ash and pulverized coal combustion (PCC) fly ash in geopolymer. Waste Manag. 2010, 30, 667-672. [CrossRef]

19. Jang, J.G.; Park, S.M.; Chung, S.; Ahn, J.W.; Kim, H.K. Utilization of circulating fluidized bed combustion ash in producing controlled low-strength materials with cement or sodium carbonate as activator. Constr. Build. Mater. 2018, 159, 642-651. [CrossRef]

20. Lin, W.T.; Weng, T.L.; Cheng, A.; Chao, S.J.; Hsu, H.M. Properties of controlled low strength material with circulating fluidized bed combustion ash and recycled aggregates. Materials 2018, 11, 715. [CrossRef]

21. Sheng, G.; Li, Q.; Zhai, J.; Li, F. Self-cementitious properties of fly ashes from CFBC boilers co-firing coal and high-sulphur petroleum coke. Cem. Concr. Res. 2007, 37, 871-876. [CrossRef]

22. Dung, N.T.; Chang, T.P.; Chen, C.T. Engineering and sulfate resistance properties of slag-CFBC fly ash paste and mortar. Constr. Build. Mater. 2014, 63, 40-48. [CrossRef]

23. Li, X.G.; Chen, Q.B.; Ma, B.G.; Huang, J.; Jian, S.W.; Wu, B. Utilization of modified CFBC desulfurization ash as an admixture in blended cements: Physico-mechanical and hydration characteristics. Fuel 2012, 102, 674-680. [CrossRef]

24. Sheng, G.; Zhai, J.; Li, Q.; Li, F. Utilization of fly ash coming from a CFBC boiler co-firing coal and petroleum coke in Portland cement. Fuel 2007, 86, 2625-2631. [CrossRef]

25. Lee, J.H.; Kim, G.Y.; Kim, Y.R.; Mun, K.J.; Nam, J.S. Engineering properties and optimal conditions of cementless grouting materials. Materials 2019, 12, 3059. [CrossRef] [PubMed]

26. Kim, Y.S.; Seo, S.G.; Ko, H.W.; Kim, J. Implementation of porous material through eco-tech for deep cement-soil mixing. Mar. Georesour. Geotechnol. 2018, 36, 931-939. [CrossRef]

27. Češnovar, M.; Traven, K.; Horvat, B.; Ducman, V. The potential of ladle slag and electric arc furnace slag use in synthesizing alkali activated materials; the influence of curing on mechanical properties. Materials 2019, 12, 1173. [CrossRef]

28. Mun, K.J. Development of non-cement material using recycled resources. Korea Inst. Build. Constr. 2014, 27, 156-157.

29. Cheon, B.S. A Study on the Soft Ground Stabilization Method by Using High-Performance Grout; National Research Foundation of Korea: Seoul, Korea, 2002.

30. Yang, H.C. Grouting Environmental Engineering; Goomiseogwan: Seoul, Korea, 2012. (In Korean)

31. Sun, J. Project Specification of Grouting Method; Seoul Metro: Seoul, Korea, 2007. (In Korean)

32. American Society for Testing and Materials. ASTM C109/C109M Standard Test Method for Compressive Strengthof Hydraulic Cement Mortars; ASTM: West Conshohocken, PA, USA, 1999.

33. Korean Industrial Standards. KS L 3317 Testing Method for Permeability to Gases of Refractory Products; Korean Agency for Technology and Standards: Eumseong-gun, Korea, 2018.

34. American Society for Testing and Materials. ASTM C1608-17 Standard Test Method for Chemical Shrinkage of hydraulic Cement Paste; ASTM: West Conshohocken, PA, USA, 2017.

(C) 2019 by the authors. Licensee MDPI, Basel, Switzerland. This article is an open access article distributed under the terms and conditions of the Creative Commons Attribution (CC BY) license (http://creativecommons.org/licenses/by/4.0/). 